\title{
Connectivity Evaluation and Planning of a River-Lake System in East China Based on Graph Theory
}

\author{
Jing Chen $\mathbb{D}^{1},{ }^{1}$ Chenguang Xiao $\mathbb{D}{ }^{1}$, and Dan Chen $\mathbb{D}^{1,2}$ \\ ${ }^{1}$ Key Laboratory of Efficient Irrigation-Drainage and Agricultural Soil-Water Environment in \\ Southern China (Ministry of Education), College of Water Conservancy and Hydropower Engineering, \\ Hohai University, Nanjing 210098, China \\ ${ }^{2}$ Department of Agricultural and Biological Engineering, The University of Florida, Gainesville, FL 32611, USA \\ Correspondence should be addressed to Chenguang Xiao; xiaochenguang@hhu.edu.cn and Dan Chen; 23543458@qq.com
}

Received 13 March 2018; Accepted 10 July 2018; Published 18 July 2018

Academic Editor: Xander Wang

Copyright (C) 2018 Jing Chen et al. This is an open access article distributed under the Creative Commons Attribution License, which permits unrestricted use, distribution, and reproduction in any medium, provided the original work is properly cited.

\begin{abstract}
The connectivity of the stream network plays an important role in water-mediated transport and river environments, which are threatened by the rugged development process in China. In this study, based on graph theory, a connectivity evaluation index system was built, which includes the Edge Connectivity, Edge-Node rate, Connectivity Reliability, and Edge Weight. The new evaluation standard and calculation method of each index is presented. The river-lake system of Fenhu industrial park in Jiangsu China is simplified to an Edge-Node graph and evaluated by the index system as a case study. The results indicate that the river-lake system of the research area has low Edge Connectivity, a high Edge-Node rate, and high reliability in the current connectivity level. In addition, the Edge Weight index of several channels does not satisfy the standard of the Basic Edge Weight. To solve the connectivity problems, specific project plans include broadening the unqualified channel and building canals linked with the low-connectivity lakes. The results show that, after the planning, the connectivity of the stream network in Fenhu industrial park will increase, and the connectivity evaluation index system is useful in the study area.
\end{abstract}

\section{Introduction}

The interconnection of a stream system is notably important, which ensures that the stream network delivers water, nutrients, and sediment through the basin and accelerates the self-cleaning ability of the system [1]. In recent years, with the rapid social and economic development in China, the rugged developing mode makes some towns or villages have serious water connectivity problems [2]. On one hand, the natural sedimentation, block, and drought retard the flow and cause the water exchange ability to decline. On the other hand, because of the pursuit of high utilization rate of land in the urbanization construction process [3], many rivers were filled or truncated to provide more construction land, which artificially intensifies the disconnected situation of the stream network and causes drainage difficulty, water quality deterioration, poor ecological environment, and many types of water problems [4-6]. Hence, studies about the interconnection of stream systems in China's urbanization process are emerging.
In recent years, the amount of research regarding stream network connectivity from different perspectives has constantly increased. From the hydrology perspective, connectivity refers to the water-mediated transport of matter, energy, and organisms within or between elements of the hydrologic cycle $[7,8]$; from the ecology perspective, river-to-lake connectivity plays an important role in water renewal and aquatic habitat diversity $[9,10]$; from the dynamics perspective, connectivity is important to the stream flow and runoff response [11]. To improve the hydraulic relationship between rivers and lakes, many engineering and nonengineering measures such as connecting project and hydrologic dispatch are used in China.

Graph theory is a theoretical model that uses an abstract method to represent the mutual relations among the study objects. The graphs in graph theory do not have characteristics such as size, shape, or mass except objects (represented by nodes) and their relations (represented by edges). The Edge-Node structure in the graph theory system is highly 
similar to the actual stream network [12]. The rivers in an actual stream network can be simplified to edges, and the lakes and junctions (points where two channels combine into one) can be simplified to nodes $[13,14]$. According to the structure characteristic of a stream network and the graph theory method, the stream network can be generalized mathematics [15]. A simplified network can be evaluated by some analysis methods of graph theory, where the connectivity of the stream network can be quantitatively analyzed. Many previous studies examined the stream network analysis using graph theory [16]. Zhao et al. evaluated the connectivity of a channel-beach system using graph theory and provided the Edge Connectivity calculation process [17]. Xu et al. combined graph theory and flow resistance theory, defined a calculation of the Edge Weight, and compared the connectivity before and after channel dredging in Taihu Basin in China [18]; Wang and $\mathrm{Xu}$ et al. analyzed the river system connectivity of Wuxi's central urban area based on graph theory and found that the river system had a decreasing trend [19]; Yang extracted the river network in Jiaodong, China, and evaluated its connectivity based on graph theory [20]. Tejedor et al. presented a framework based on the spectral graph theory and constructed vulnerability maps in the river deltas using the framework [21].

However, in previous studies, most researchers used single indicators to analyze the connectivity of stream networks, which introduced many problems caused by the limitations of individual indices. For example, the Edge Connectivity index can reflect the interrelationship of the nodes but cannot reflect the size of the rivers, and the Edge Weight index is the opposite. Nevertheless, different indicators of graph theory are rarely combined to make a comprehensive analysis of stream systems. In addition, little attention has been paid to the connectivity evaluation for river-lake systems (stream networks with numerous lakes) and the specific project guidance after the evaluation.

The objectives of this study are to (1) select a typical stream network with numerous lakes and abstract it based on graph theory, (2) establish a multidimension evaluation method to estimate the interconnectivity level of the riverlake system, and (3) use specific projects to improve the connectivity of the study area. First, we select the river-lake system of Fenhu industrial park in China as the study area and simplify it to an Edge-Node graph. Second, we build a connectivity evaluation index system that includes the Edge Connectivity, Edge-Node rate, Connectivity Reliability, and Edge Weights, and we explain the meaning and evaluation criterion of each index. Finally, we evaluate the connectivity of the river-lake system in Fenhu using the evaluation system and provide specific project planning to solve the connectivity problems.

\section{Study Area and Methods}

2.1. Study Area. We use Fenhu industrial park in Jiangsu province, East China, as the research area (Figure 1). Fenhu industrial park belongs to Taihu Basin with an area of $258 \mathrm{~km}^{2}$ and a population of 250 thousand. It has subtropical monsoon climate with plenty of rainfall and four distinct seasons [22].
The area is located on the flood plain with a ground elevation of 2.20-5.20 m and mostly belongs to polder areas. Because of the natural factors, the water level, flow direction, and velocity of the stream often vary.

The study area has a typical stream network structure in flood plains in China with flat, shallow, and narrow channels, a disordered river-lake system, deficient connectivity between rivers and lakes, serious sedimentation, and low draining capability. In addition, because the area is located in the downstream location of Taihu Lake (China's second largest lake), it is easily threatened by flood disasters. Thus, Fenhu industrial park consists of several polder areas to prevent the inner polder areas from being threatened by flooding. The stream system of each polder area is separated by the dike, sluice, and dam, which make the inner polder area independent from the outside. This setting also introduces many problems such as insufficient flood control and drainage ability, standard-exceeding of water quality, and ecosystem destruction. Because of the relative independence of the inner polder area, in this study, we ignore the inner area and select the outer polder area as the research object (Figure 2).

2.2. River-Lake System Simplification. In this study, we focus on the connectivity of the stream network outside the polder area; we only identify and extract the outer rivers and lakes on the map using labels. As shown in Figure 3(a), following the principle of graph theory, we use numbers to represent lakes and junctions and circled numbers to represent rivers.

After identifying the research objects, we simplify the lakes and river junctions to nodes and the rivers to edges. Because the flow direction in the study area often changes with the climate and rainfall, we define the rivers as undirected edges [23]. As shown in Figure 3(b), there is a simplified, undirected stream network graph that reflects the relationship between rivers and lakes. The research below is based on the simplified stream network graph.

2.3. Connectivity Evaluation Index System. Many indices in graph theory can evaluate the connectivity, for example, the Edge Connectivity, Edge-Node rate, Actual Ring Formation rate, Network Connection degree, and Edge Weights. Currently, there is no unified and complete evaluation index system to perfectly and synthetically evaluate the connectivity of a stream network. In this paper, based on the principles of comprehensiveness, diversity, and operability, four indices (Edge Connectivity, Edge-Node rate, Connectivity Reliability, and Edge Weights) are set as a connectivity evaluation index system (Table 1). In the system, the indices of Edge Connectivity, Edge-Node rate, and Edge Weights are generally used in the graph theory; the Connectivity Reliability is created in this paper for the first time. Through this connectivity evaluation index system, the connectivity of the stream network can be better evaluated. We will introduce the meaning, calculation, and evaluation standard of each index in this system below.

2.3.1. Edge Connectivity. The Edge Connectivity is equal to the minimum number of edges, which must be removed to make an unconnected graph, with notation $\lambda$. The Edge 


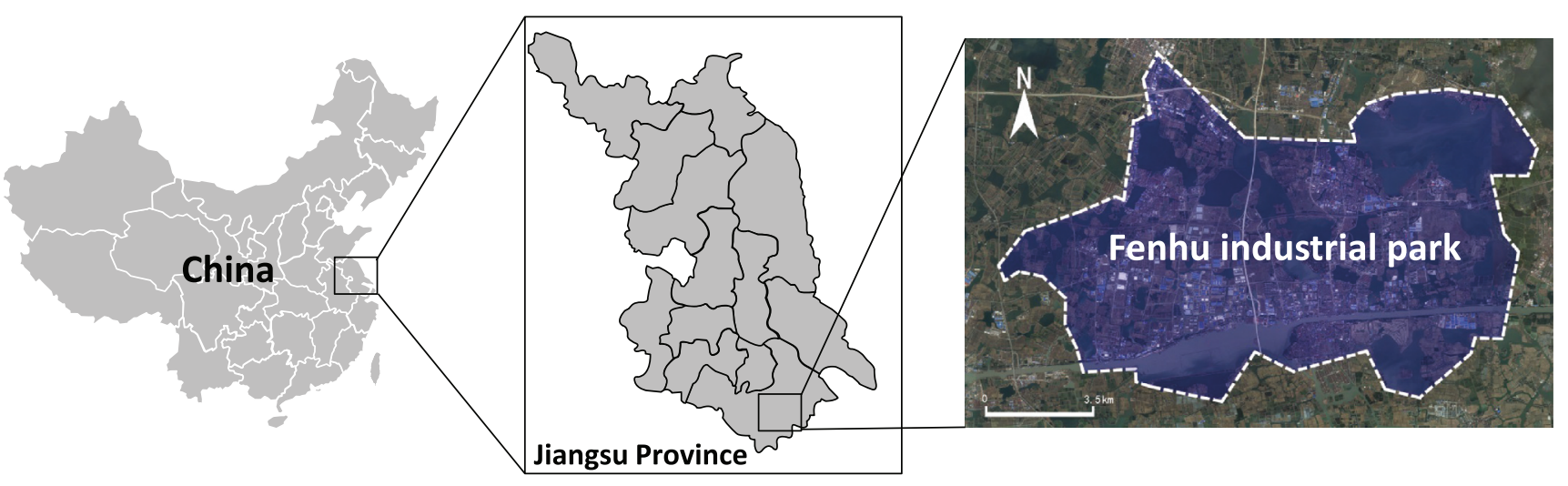

FIGURE 1: Location of the study area in Jiangsu province, East China.

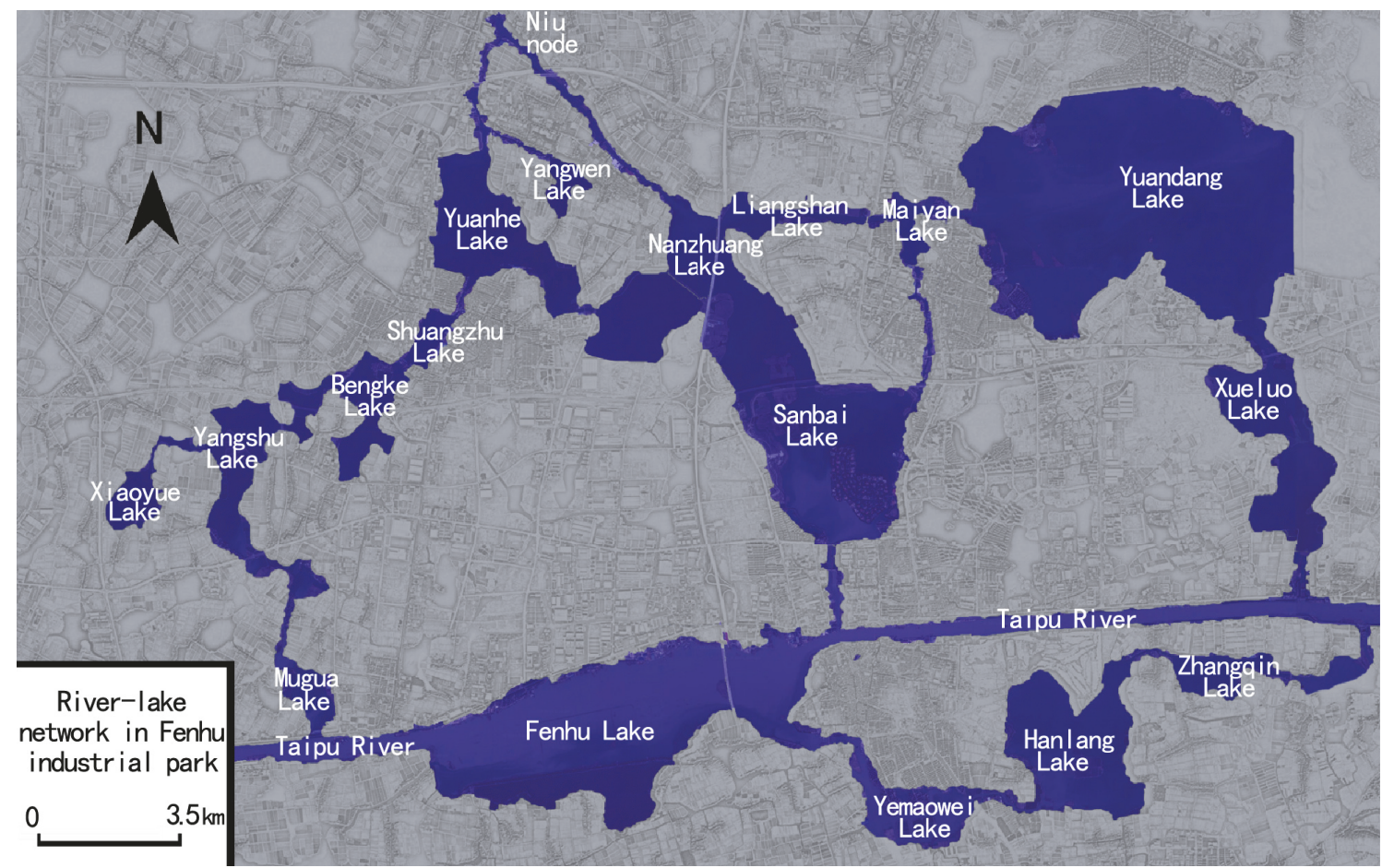

FIGURE 2: River-lake system of Fenhu industrial park; the blue portion is outer polder area.

TABLE 1: Connectivity evaluation index system.

\begin{tabular}{|c|c|c|c|}
\hline Classification & Index & Meaning & Evaluation content \\
\hline $\begin{array}{l}\text { Determinant } \\
\text { index }\end{array}$ & Edge Connectivity $\lambda$ & $\begin{array}{l}\text { The minimum number of edges that must be } \\
\text { removed to make a graph unconnected. }\end{array}$ & $\begin{array}{l}\text { Evaluate the connectivity of the entire } \\
\text { stream network. }\end{array}$ \\
\hline \multirow{3}{*}{$\begin{array}{l}\text { Evaluative } \\
\text { index }\end{array}$} & $\begin{array}{l}\text { Edge-Node rate } \\
\beta\end{array}$ & $\begin{array}{c}\text { Divide the number of rivers by the number } \\
\text { of lakes and junctions. }\end{array}$ & $\begin{array}{l}\text { Evaluate the number of rivers that each node } \\
\text { occupies. }\end{array}$ \\
\hline & $\begin{array}{c}\text { Connectivity Reliability } \\
P_{\lambda}\end{array}$ & $\begin{array}{l}\text { The possibility of the Edge Connectivity } \\
\text { remains unchanged if one edge is randomly } \\
\text { disconnected in a system with Edge } \\
\text { Connectivity } \lambda \text {. }\end{array}$ & $\begin{array}{c}\text { Evaluate the reliability of a stream network } \\
\text { in the current Edge Connectivity level. } \\
\text { The range is from } 0 \text { to } 1\end{array}$ \\
\hline & $\begin{array}{l}\text { Edge Weights } \\
\qquad A\left(\mathrm{~m}^{2}\right)\end{array}$ & River section. & Evaluate the discharge capacity of rivers. \\
\hline
\end{tabular}




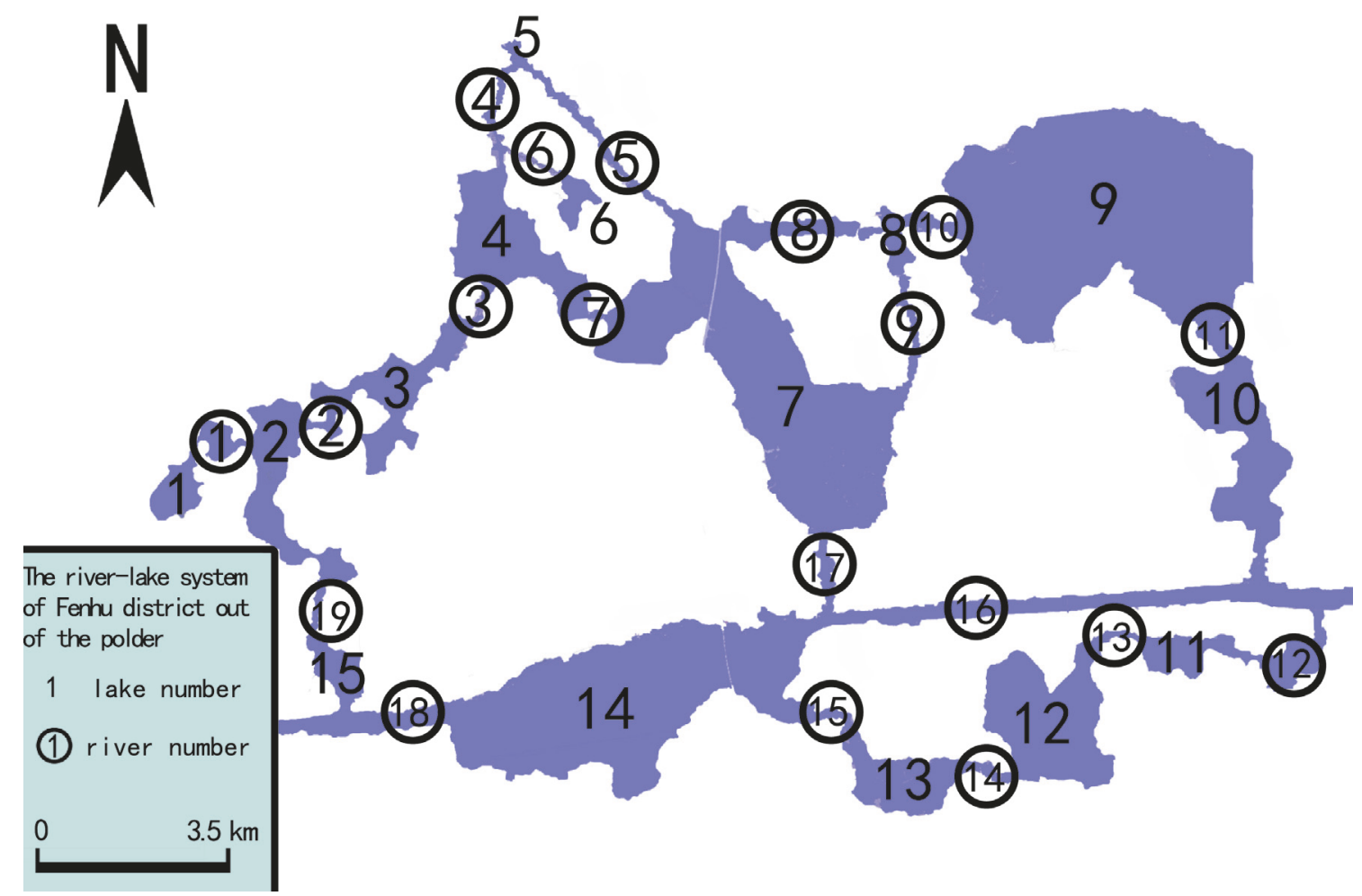

(a)

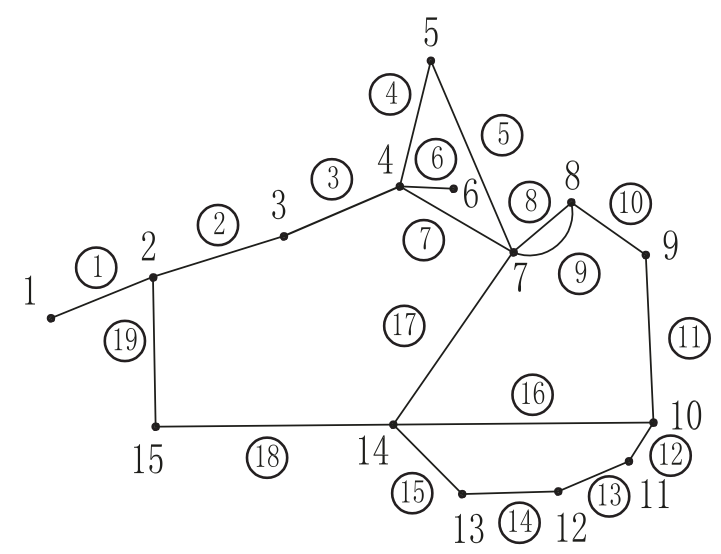

1 Lake number

(1) River number

(b)

Figure 3: (a) River-lake system of the research area outside the polder. (b) Simplified stream network graph of Fenhu industrial park.

Connectivity of an unconnected graph is zero. Graphs with high Edge Connectivity must remove more edges to become an unconnected graph; they have strong connectivity and are difficult to break. In an actual drainage basin, the poor connectivity of a small area always becomes the source of weak flood control ability, deteriorative water quality, and poor ecosystem of the entire basin. The Edge Connectivity index can precisely reflect the extent of the weakest link area in the stream network and use it to represent the connectivity of the entire system. The Edge Connectivity is the determinant index in an evaluation system, by which we classified the networks.

The unconnected stream networks contain isolated lakes, ponds, or independent small subnetworks (e.g., node $n_{1}$ in Figure 4(a)). The connectivity of these parts is notably poor, and they almost cannot have water exchange with one 


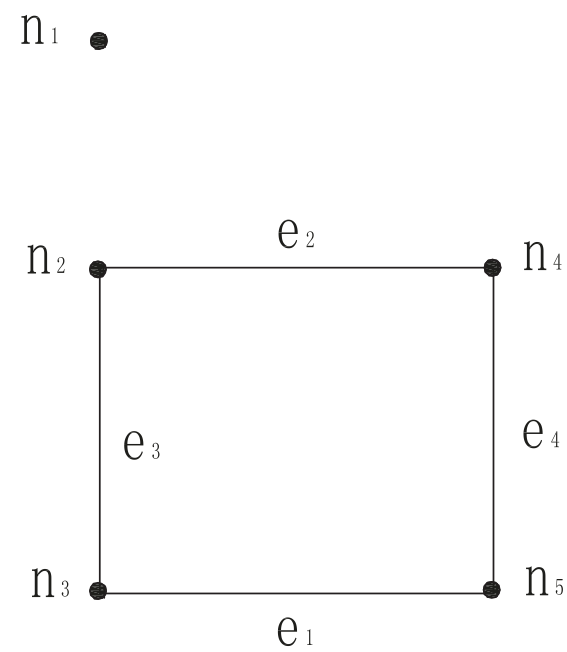

(a)

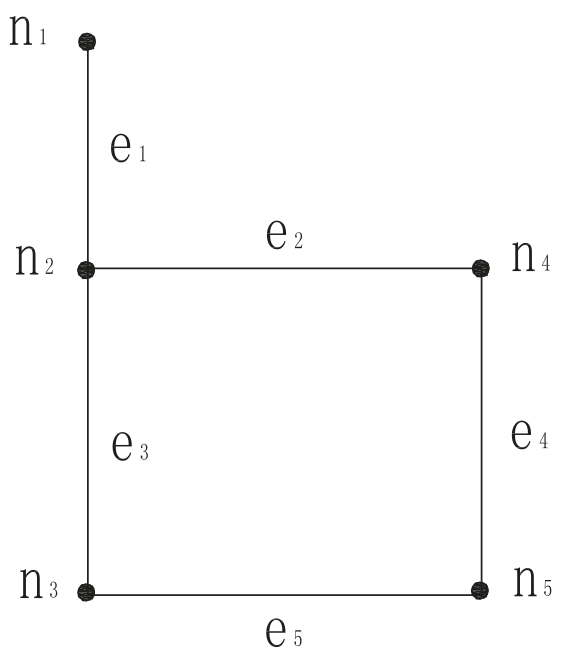

(b)

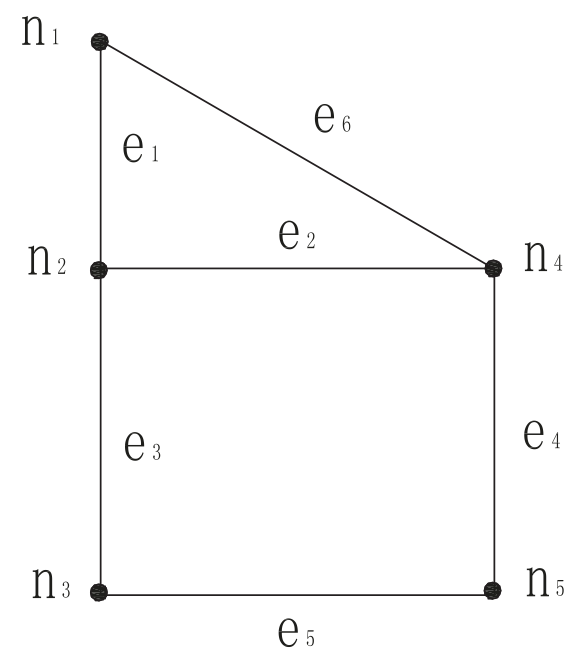

(c)

Figure 4: (a) Unconnected graph. (b) Connected graph with an Edge Connectivity of 1. (c) Connected graph with an Edge Connectivity of 2 .

another. Thus, an unconnected stream network has a notably poor interconnectivity, which is the unacceptable drainage structure form.

To the stream network, where the Edge Connectivity is 1 (Figure $4(\mathrm{~b})$ ), the connectivity of the network remains poor. The lakes whose degree (number of edges that link with the node) is 1 cannot smoothly exchange water with other lakes (e.g., node $n_{1}$ in Figure 4(b)). It may cause water quality deterioration and allow the deteriorating water to be transmitted to the entire stream network. Thus, a system with an Edge Connectivity of 1 is also unacceptable.

To the stream network, when the Edge Connectivity is 2 (Figure 4(c)), every lake is at least linked with two other lakes as part of a closed loop. The in-out water-delivering channel of the lakes can be build. The pollutant in the stream network will be self-cleaned by a cycle in the loop. Thus, the system with an Edge Connectivity of 2 is acceptable.

To the stream network with Edge Connectivity at 3 or more, the connect abilities between lakes are generally more perfect. The water exchange is smooth, so it is the ideal stream network structure.

2.3.2. Edge-Node Rate. The Edge-Node rate is obtained by dividing the number of rivers by the number of lakes as follows:

$$
\beta=\frac{L}{N}
$$

where $\beta$ is the Edge-Node rate, $L$ is the number of rivers, and $N$ is the number of lakes or junctions. The Edge-Node rate can reflect the relative density of rivers. This important index can evaluate the connectivity of the entire system. The system with a high Edge-Node rate commonly has a developed stream network, and each lake occupies more rivers.

For the connected network, an Edge-Node rate less than 1 indicates that the stream network is too thin, each lake averagely occupies less than 1 river, and there is no ring structure to circulate water in the network. Hence, it is an unacceptable Edge-Node rate number. When the Edge-Node rate is equal to 1 , there is one ring structure in the system (e.g., Figure 4(b)). When the Edge-Node rate is larger than 1 , there are two or more ring structures in the system, and the structure of the stream network is more complex (e.g., Figure 4(c)). Thus, the Edge-Node rate should be larger than one to satisfy the connectivity requirement.

2.3.3. Connectivity Reliability. The common connectivity index sometimes cannot reflect the different structures of two similar-size systems, so the Connectivity Reliability index has been created.

The Connectivity Reliability is the possibility of the Edge Connectivity remaining unchanged if one edge randomly disconnects; for a network whose Edge Connectivity is $\lambda$ (formula (2)), we have

$$
P_{\lambda}=\frac{E}{L} \quad\left(0 \geq P_{\lambda}>1\right)
$$

where $P_{\lambda}$ is the Connectivity Reliability of the network with an Edge Connectivity of $\lambda, E$ is the number of edges that can be removed while keeping the Edge Connectivity invariable, and $L$ is the number of all edges in the system.

The Connectivity Reliability has a notably adaptive practical significance: it can simulate the possibility of connectivity reducing by river blocking because of perennial sedimentation or geological disasters. At a certain Edge Connectivity, the stream network structure will become more reliable when the Connectivity Reliability index approaches 1 and more unreliable when it approaches 0 . The systems with high Connectivity Reliabilities have a strong ability to resist river breaking; that is, even if a river breaks, the impact will be small. When the Connectivity Reliability is equal to 1 , the Edge Connectivity will increase by a level. The Connectivity 
TABLE 2: Connectivity Reliability evaluation scale.

\begin{tabular}{lcccr}
\hline Connectivity Reliability & {$[\mathbf{0 . 0 0}, \mathbf{0 . 2 5})$} & {$[\mathbf{0 . 2 5}, \mathbf{0 . 5 0})$} & {$[\mathbf{0 . 5 0 , 0 . 8 5 )}$} & {$[\mathbf{0 . 8 5}, \mathbf{1 . 0 0 )}$} \\
\hline Rating & Very unreliable & Unreliable & Reliable & Very reliable \\
\hline
\end{tabular}

Reliability cannot be compared when the systems have two different Edge Connectivity levels.

According to statistical analysis and experience, the relationship between the Connectivity Reliability index and the actual stream network is built (Table 2).

2.3.4. Edge Weights. In graph theory, many river characteristics such as the length, width, and depth have been neglected. However, in actual stream networks, some characteristics have obvious effects on the interconnectivity. Thus, the Edge Weight index is developed and can be used to simulate the actual river forms. Many characteristics can affect the river discharge capacity, such as the flow section area, flow velocity, geometrical shape, length, slope, roughness, and evaporation. However, because the research area is flat, the slope tends to be zero, and the flow velocity is notably slow; other characteristics are subordinate and difficult to precisely measure in actual situations. Thus, the flow section of rivers is set as the Edge Weights, which is denoted by $A_{e}$. This index has the largest effect on the river discharge capacity.

Rivers with high Edge Weights have large flow section and high discharge capacity to improve the connectivity of the stream network. There are different standards of Edge Weights in different research areas and situations. In this paper, for the lakes concentration areas south of Jiangsu, an evaluation criterion of Edge Weights is created, respectively, from the view of lakes and rivers.

(1) Basic Total River Flow Section to Lakes. The sum of the river flow section areas that are linked with lake $n$ is called the Total River Flow Section of lake $n$, which is denoted by $M_{n}$. Lakes with larger $M_{n}$ have greater water exchange capacity and selfcleaning ability. A lake with more water commonly requires larger $M_{n}$. Thus, to analyze whether $M_{n}$ satisfies the lake connectivity requirement, the Basic Total River Flow Section is created and denoted by $M_{k n}$. Its relationship with the water volumes is given in the following formula:

$$
M_{k n}=\omega V_{n}
$$

where $M_{k n}$ is the Basic Total River Flow Section linked with lake $n\left(\mathrm{~m}^{2}\right)$; $\omega$ is the Total River Flow Section Coefficient $\left(\mathrm{m}^{2} / \mathrm{m}^{3}\right) ; V_{n}$ is the water volume of lake $n\left(\mathrm{~m}^{3}\right)$, calculated by the ordinary water level. $M_{k n}$ is the minimum $M_{n}$ that the lakes require. When $M_{n}$ is greater than $M_{k n}$, the basic connectivity of the lake satisfies the demand. When $M_{n}$ is less than $M_{k n}$, the system cannot satisfy the basic connectivity demand and must be improved. Coefficient $\omega$ must be adjusted according to the specific situation of the study area.

(2) Basic Edge Weight. The Basic Edge Weight is the minimum flow section area that the rivers must have to satisfy the connectivity demand and is denoted by $A_{k e}$. Lakes connect with other lakes through rivers or channels; because of different water transmission quantities, the connection between large lakes commonly requires a large river flow section. The river flow section and size of lakes linked with the river have a strong positive correlation. Thus, their relationship can be built to find the Basic Edge Weights as follows:

$$
\begin{aligned}
A_{k a} & =\frac{M_{k a} V_{b}}{\sum V_{t a}} \\
A_{k b} & =\frac{M_{k b} V_{a}}{\sum V_{t b}} \\
A_{k e} & =\max \left(A_{k a}, A_{k b}\right)
\end{aligned}
$$

where $a, b$ are the numbers of lakes connected by river e; $A_{k a}$ is the Basic Edge Weight of river $e$ calculated from lake $a\left(\mathrm{~m}^{2}\right)$; $A_{k b}$ is the Basic Edge Weight of river $e$ calculated from lake $b\left(\mathrm{~m}^{2}\right) ; M_{k a}$ is the Basic Total River Flow Section of Lake $a$ $\left(\mathrm{m}^{2}\right) ; M_{k b}$ is the Basic Total River Flow Section of lake $b\left(\mathrm{~m}^{2}\right)$; $V_{a}$ is the volume of lake $a\left(\mathrm{~m}^{3}\right) ; V_{b}$ is the volume of lake $b$ $\left(\mathrm{m}^{3}\right) ; \sum V_{t a}$ is the total volume of all lakes connected with lake $a\left(\mathrm{~m}^{3}\right) ; \sum V_{t b}$ is the total volume of all lakes connected with lake $b\left(\mathrm{~m}^{3}\right) ; \mathrm{A}_{\mathrm{ke}}$ is the Basic Edge Weight of river $e\left(\mathrm{~m}^{2}\right)$. The formula is calculated, respectively, from two lakes linked by river $e$. Firstly, We assign $M_{k a}$ and $M_{k b}$ to river $e$ to obtain $A_{k a}$ and $A_{k b}$; then we take the maximum of those two as $A_{k e}$ (Figure 5(a)).

When the realistic flow section of a river is larger than the Basic Edge Weight, we consider that the river satisfies the demand of basic connectivity. If every River Flow Section in the system is larger than the Basic Edge Weight, the entire stream system is considered to be smoothly running.

A special drainage structure will sometimes affect the accuracy of the calculation. For example, when two large lakes are connected by a notably small lake, the calculation results may be small and do not affect the actual situation (Figure 5(b)). Thus, we must make some adjustments according to the actual condition in the calculation, such as ignoring the small lakes and directly selecting two large lakes as the research lakes.

2.4. Research Procedure. The research method is summarized in three steps. (1) According to the actual river-lake relationship, abstract the stream network to a nodes-edges graph based on graph theory; (2) bring characteristic data into the connectivity evaluation index system to estimate the connectivity level of the river-lake system; and (3) develop connectivity planning including specific projects to improve the connectivity of the study area (Figure 6).

\section{Results and Discussion}

\subsection{Connectivity Evaluation of Fenhu Industrial Park}

3.1.1. Edge Connectivity. In the simplified stream network graph (Figure $3(\mathrm{~b})$ ), every node links to others and makes 


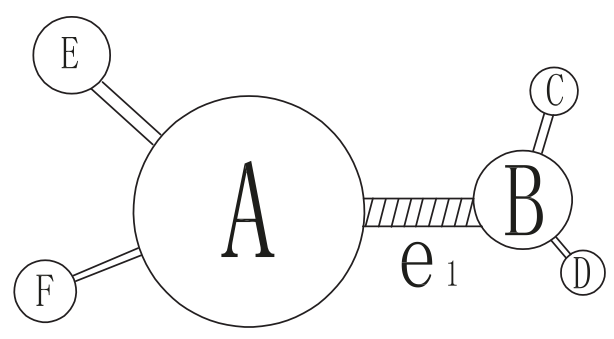

(a)

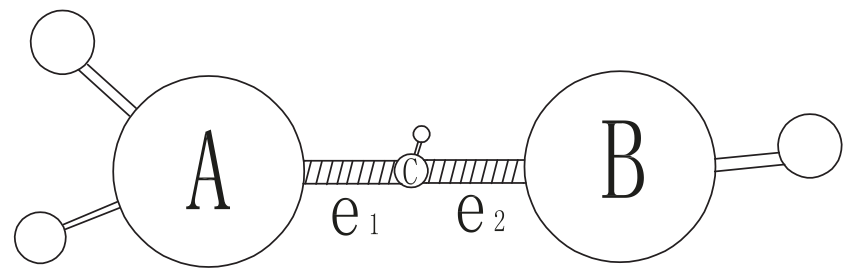

(b)

FIgURE 5: (a) Basic Edge Weight calculation illustration. (b) Basic Edge Weight calculation illustration in a special situation.

STEPS METHOD DATA

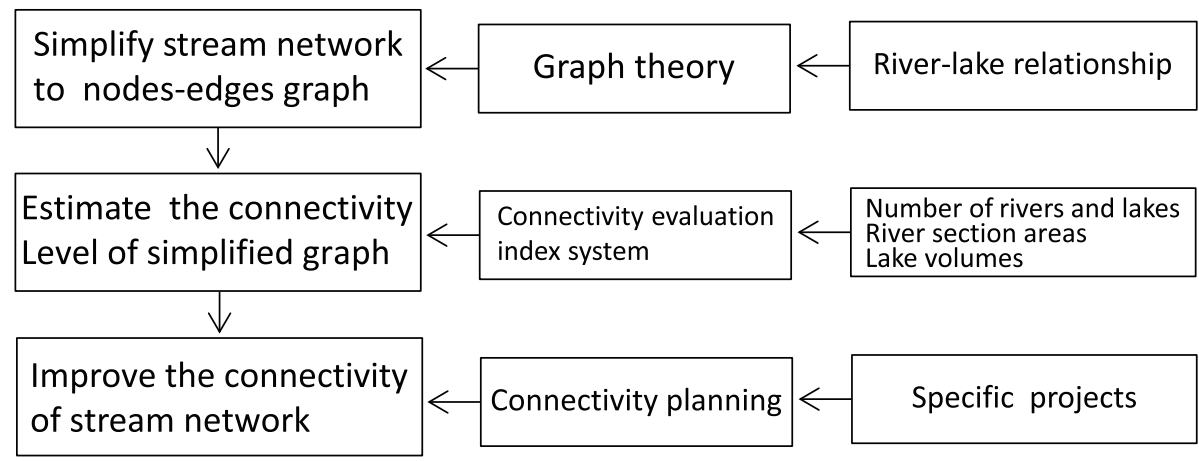

Figure 6: Flowchart.

the graph a connected graph. If we remove one specific edge (edge 1 or edge 6 ), node 1 or node 6 will be separated from the entire network, which makes the system disconnected. Thus, the Edge Connectivity of the current network is 1.

3.1.2. Node-Edge Rate. There are 15 nodes and 19 edges in the graph. According to formula (1), the Node-Edge Rate is 1.27 , which indicates that the stream network construction is complex and has more than two cyclic structures.

3.1.3. Connectivity Reliability. After we remove edge 1 or edge 6 , the Edge Connectivity will be reduced to 0 , and other rivers will not affect the Edge Connectivity if any one of them is removed. According to formula (2), the Connectivity Reliability $P_{1}$ is 0.89 , which is in the range of $[0.85,1.00]$; that is, the stream network is notably reliable in the current connectivity level (Table 2).

3.1.4. Edge Weight. The Edge Weight of each river is its river section area, as listed in Table 4. To avoid the influence of river and lake sizes varying and ensure the accuracy of the calculation, all the data we used are up to date. To determine whether the flow sections satisfy the evaluation standard, we should calculate $M_{k n}$ and $A_{k e}$.

(1) Calculation of the Basic Total River Flow Section of Lakes $M_{k n}$. The Total River Flow Section of lake $n\left(M_{n}\right)$ is calculated by adding all connected river sections of lake $n$. According to the practical situation in the study area and research experience, the Total River Flow Section Coefficient $\omega$ is defined as $0.00006 \mathrm{~m}^{2} / \mathrm{m}^{3}$, which implies that every 100000 cubic meters of water need 6 square meters of flow section area to ensure that the lake smoothly runs. Using formula (3), we can obtain $M_{k n}$ of each lake, from which we subtract $M_{n}$ to obtain the Shortage of Total River Flow Section $M_{\Delta}$ (Table 3).

When $M_{\Delta}$ is positive, the lake does not have sufficient drainage channel area, and we must increase $M_{n}$ to $M_{k n}$. When $\mathrm{M}_{\Delta}$ is negative, $M_{n}$ need not be changed. According to Table 3, lakes 1, 2, 3, 6, 7, and 12 should adjust the flow section around them to satisfy the basic requirement of $M_{k n}$.

(2) Calculation of Basic Edge Weight $A_{k e}$. Based on formula (4), we can find two sets of Basic Edge Weight and select the larger one as $A_{k e}$, which subtract the current river section to obtain the Shortage of River Section $\left(A_{\Delta}\right)$, as shown in Table 4.

When we calculate the Basic Edge Weights of rivers 8, 9, and 10, we select node 7 (Sanbai Lake) and node 9 (Yuan Lake) as lake $a$ and lake $b$ and ignore the small lake 8 (Maiyan) to ensure a correct and reasonable result. When $A_{\Delta}$ is positive, the River Flow Section is not sufficiently large and we must increase $A_{e}$ to $A_{k e}$. When $A_{\Delta}$ is negative, $A_{e}$ need not be changed. According to Table 4, rivers 1, 2, 3, 6, 7, 14, 17, and 19 have different insufficient situations in the river section area.

The above calculation and analysis show that the connectivity condition of the river-lake network in Fenhu industrial park is not sufficient. The problems of low Edge Connectivity, narrow channel, and insufficient flow section threaten the local water security and water environment. Therefore, the 
TABle 3: Calculation of Total River Flow Section of lakes.

\begin{tabular}{|c|c|c|c|c|c|}
\hline $\begin{array}{l}\text { Lake } \\
\text { number } n\end{array}$ & Lake name & $\begin{array}{l}\text { Volume of lake } \\
\qquad n V_{n}\left(\mathrm{~m}^{3}\right)\end{array}$ & $\begin{array}{c}\text { Total River } \\
\text { Flow Section } \\
\text { of lake } n M_{n} \\
\left(\mathrm{~m}^{2}\right)\end{array}$ & $\begin{array}{l}\text { Basic Total River } \\
\text { Flow Section of } \\
\text { lake } n M_{k n}\left(\mathrm{~m}^{2}\right)\end{array}$ & $\begin{array}{c}\text { Shortage of } \\
\text { Total River } \\
\text { Flow Section } \\
M_{\Delta}\left(\mathrm{m}^{2}\right) \\
\end{array}$ \\
\hline 1 & Xiaoyue Lake & 310000 & 7.42 & 18.60 & 11.18 \\
\hline 2 & $\begin{array}{c}\text { Shaobo Lake, } \\
\text { etc. }\end{array}$ & 750000 & 17.51 & 45.00 & 27.49 \\
\hline 3 & $\begin{array}{l}\text { Bengke Lake, } \\
\text { etc. }\end{array}$ & 580000 & 34.69 & 34.80 & 0.11 \\
\hline 4 & Yuanhe Lake & 1830000 & 172.61 & 109.80 & -62.81 \\
\hline 5 & Niu Node & 30000 & 149.52 & 1.80 & -147.72 \\
\hline 6 & $\begin{array}{c}\text { Yangwen } \\
\text { Lake }\end{array}$ & 180000 & 10.42 & 10.80 & 0.38 \\
\hline 7 & $\begin{array}{c}\text { Sanbai Lake, } \\
\text { etc. }\end{array}$ & 7386666 & 564.17 & 443.20 & -121.0 \\
\hline 8 & Maiyan lake & 320000 & 582.42 & 19.20 & -563.22 \\
\hline 9 & Yuan Lake & 9930000 & 689.10 & 595.80 & -93.3 \\
\hline 10 & Xueluo Lake & 982000 & 961.39 & 58.92 & -902.47 \\
\hline 11 & $\begin{array}{c}\text { Zhangqing } \\
\text { Lake }\end{array}$ & 450000 & 102.03 & 27.00 & -75.03 \\
\hline 12 & Hanlang Lake & 2150000 & 101.94 & 129.00 & 27.06 \\
\hline 13 & $\begin{array}{l}\text { Yemaowei } \\
\text { Lake }\end{array}$ & 250000 & 91.67 & 15.00 & -76.67 \\
\hline 14 & Fenhu Lake & 3150000 & 1982.61 & 189.00 & -1793.61 \\
\hline 15 & Mugua Lake & 520000 & 952.02 & 31.20 & -920.82 \\
\hline
\end{tabular}

TABLE 4: Calculation of Basic Edge Weight.

\begin{tabular}{|c|c|c|c|}
\hline $\begin{array}{l}\text { River } \\
\text { number } \\
e \\
\end{array}$ & $\begin{array}{l}\text { River section area } \\
\qquad A_{e}\left(\mathrm{~m}^{2}\right)\end{array}$ & $\begin{array}{l}\text { Basic Edge Weight } \\
\text { of river } e A_{k e}\left(\mathrm{~m}^{2}\right)\end{array}$ & $\begin{array}{c}\text { Shortage of river } \\
\text { section } \\
A_{\Delta}\left(\mathrm{m}^{2}\right) \\
\end{array}$ \\
\hline 1 & 7.42 & 18.60 & 11.18 \\
\hline 2 & 10.09 & 29.33 & 19.24 \\
\hline 3 & 24.60 & 24.68 & 0.09 \\
\hline 4 & 65.95 & 0.40 & -65.55 \\
\hline 5 & 83.57 & 1.44 & -82.12 \\
\hline 6 & 10.42 & 10.80 & 0.38 \\
\hline 7 & 71.64 & 99.19 & 27.55 \\
\hline 8 & 269.64 & 288.40 & -24.38 \\
\hline 9 & 43.14 & 288.40 & -24.38 \\
\hline 10 & 269.64 & 11.48 & -258.16 \\
\hline 11 & 136.37 & 43.23 & -93.14 \\
\hline 12 & 15.36 & 8.47 & -6.89 \\
\hline 13 & 86.68 & 82.93 & -3.75 \\
\hline 14 & 15.26 & 46.07 & 30.81 \\
\hline 15 & 76.41 & 8.92 & -67.49 \\
\hline 16 & 926.57 & 17.79 & -908.77 \\
\hline 17 & 96.18 & 133.71 & 37.53 \\
\hline 18 & 933.78 & 9.42 & -924.36 \\
\hline 19 & 13.72 & 26.29 & 12.57 \\
\hline
\end{tabular}




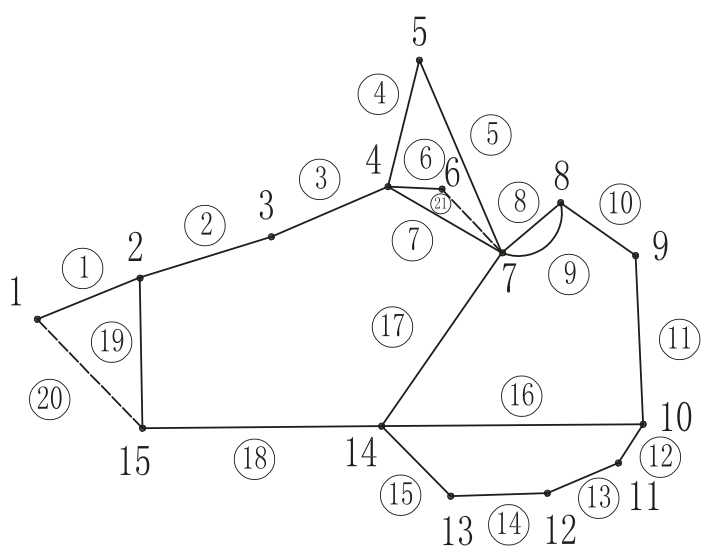

1 Lake number

River number

(a)

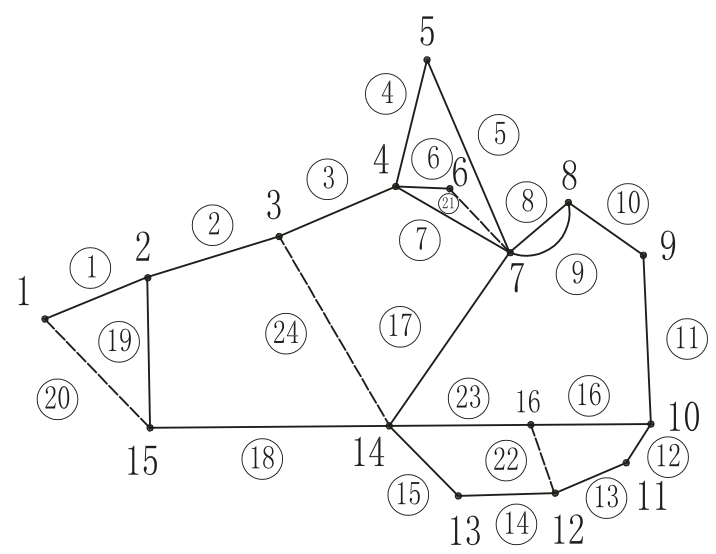

1 Lake number

\section{River number}

FIGURE 7: (a) Simplified stream network after the first-phase planning. (b) Simplified stream network after the second-phase planning.

transformation plan targeted on the river-lake system in the study area to enhance the current connectivity situation is urgently required.

3.2. Transform Plan of the River-Lake System in Fenhu Industrial Park. Based on the current connectivity evaluation in Section 3.1, a connectivity improvement plan is provided with two phases. The first phase aims to make the stream network essentially unimpeded under the limited manpower, material resources, and financial resources. The second phase aims to solve most connected problems to make the riverlake network more unimpeded and smooth. The connectivity condition in the study area will be improved after the two phases.

3.2.1. First-Phase Planning. In Fenhu industrial park, the Edge Connectivity of the river-lake network is 1 , which is unacceptable. Because the insufficient connection of nodes 1 and 6 may cause a part of stream network to decrease in water exchange efficacy and deterioration of water quality, which will affect the regional water environment, we must increase the Edge Connectivity. In addition, the Connectivity Reliability is sufficiently large, so a few connection projects can improve the Edge Connectivity, and the plan is feasible.

More specifically, we should focus on linking Xiaoyue Lake (node 1) and Yangwen Lake (node 6) to the entire stream network to increase the Edge Connectivity. According to the design philosophy of low work quantity and respecting the natural river morphology, we attempt to minimize digging new rivers, demolition, and immigration in the project process. Based on the local situation, we connect the water channels between Xiaoyue Lake (node 1) and Mugua Lake (node 15) and between Yangwen Lake (node 6) and Sanbai Lake (node 7). The new water channels are constituted by the surrounding unconnected rivers and lakes in the polder.
Figure 7 (a) shows the simplified graph after the connection; the new channels are named edge 20 and edge 21 as shown with dotted lines. After the primary improvement, the Edge Connectivity of the system has been increased to 2 , which is acceptable.

3.2.2. Second-Phase Planning. After the first phase, the stream network is relatively unobstructed but can be further improved. Because of the difficulty of adding new rivers to increase the Edge Connectivity to 3 and because 2 is an acceptable Edge Connectivity value, we decide to improve the connectivity using other indices.

(1) Improve the Connectivity by Increasing the Connectivity Reliability. After the first phase, the Connectivity Reliability $P_{2}$ becomes 0.33 , which belongs to the unreliable scale and should be improved (Table 2). Following the principle of best comprehensive benefits, we select the edge that can increase the Connectivity Reliability as much as possible and minimize the damage on the local original channel. Thus, we link Bengke Lake (node 3) with Fenhu Lake (node 14) and Hanlang Lake (node 12) with Taipu River (new node 16). Both projects use the existing rivers and lakes in the polder to avoid the disturbance. The simplified graph is shown in Figure 7(b), and the new channels are named edge 22 and edge 24 as shown with dotted lines.

(2) Improve the Connectivity by Increasing the Edge Weight. According to the analysis of Table $3, M_{\Delta}$ of some lakes are positive, which implies that the rivers around these lakes must be widened to satisfy the $M_{k n}$ requirement. According to the analysis of Table $4, A_{\Delta}$ of some rivers are positive, which implies that we must broaden these rivers to satisfy the $A_{k e}$ requirement.

The narrow rivers mainly appear around Shaobo Lake (node 2) and Sanbai Lake (node 7). Based on the calculation, 


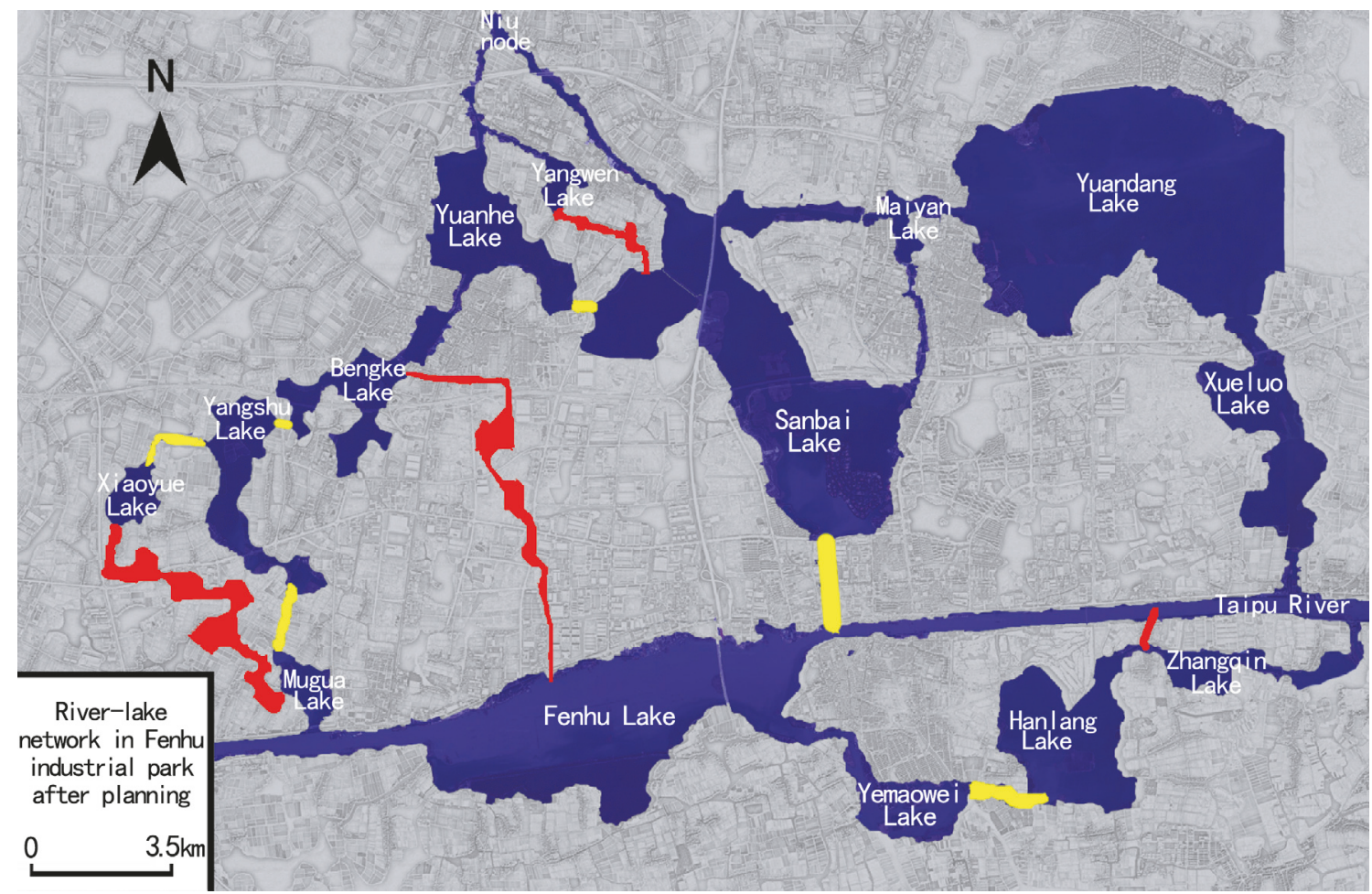

FIGURE 8: River-lake network in Fenhu industrial park after planning. The red line represents the connecting projects, and the yellow line represents the widening projects.

we must desilt the rivers that link Xiaoyue Lake (node 1), Bengke Lake (node 3), and Mugua Lake (node 15) with Shaobo Lake (node 2) and broaden the rivers that link Yuanhe Lake (node 4) and Fenhu Lake (node 14) with Sanbai Lake (node 7). In addition, the flow section between Yemaowei Lake (node 13) and Hanlang Lake (node 12) is not sufficiently large and must be desilted. Thus, 6 rivers (river 1, river 2, river 7 , river 14 , river 17 , and river 19 ) must be desilted or broadened. Because the new rivers 21 and 24 reduce the drainage stress of rivers 3 and 6 , after the connecting projects, those two narrow rivers can satisfy the standard. After several specific project measures, the flow section of those rivers will be as follows: river 1: $16.52 \mathrm{~m}^{2}$; river 2: $30.24 \mathrm{~m}^{2}$; river $7: 116.34 \mathrm{~m}^{2}$; river 14: $39.05 \mathrm{~m}^{2}$; river 17: $138.18 \mathrm{~m}^{2}$; river 19: $27.18 \mathrm{~m}^{2}$.

3.3. Discussion. After two phases, the connectivity indices of the study area are changed. The Edge Connectivity is changed to 2, which implies that every lake is at least linked with two other lakes to compose a closed loop. The in-out waterdelivering channel of each lake can be built, and the pollutant in the stream network will be self-cleaned by the cycle in the loop; there are 24 edges and 16 nodes in the graph, so the Edge-Node rate is 1.5; that is, the structure becomes more complex and more conducive to water exchange. Among all 24 edges, if we remove any edge in a group of 12 edges (edges 2, 3, 7, 8, 9, 16, 17, 18, 19, 22, 23, and 24), the Edge Connectivity will not change. Hence, in the situation where Edge Connectivity is 2, the index of Connectivity Reliability $\mathrm{P}_{2}$ is 0.5 , which is in the reliable range. Two new edges (edges 20 and 21) are added to the Edge Weight index. The calculation results show that both $M_{\Delta}$ and $A_{\Delta}$ are negative after the projects, which indicates that all rivers satisfy the demand of minimum flow section area. All projects in planning are shown in Figure 8, including 4 connecting projects and 6 widening projects. All indices satisfy the standard requirements according to the connectivity evaluation index system. The connectivity between rivers and lakes is unobstructed, and the water security and water environment goals can be basically achieved.

The results show that the connectivity planning is effective. However, if the size of the river-lake system changes due to erosion and so forth in the future, we should use the evaluation system and the new data to reevaluate its connectivity. We still need to further validate the effectiveness of the evaluation system by investigating the actual connectivity of study area after the completion of the specific projects. In addition, more statistical analysis is needed to cross-validate the evaluation in the future to verify the universal applicability.

\section{Conclusion}

In this paper, based on the graph theory, we have built a connectivity evaluation index system of the river-lake system and introduced the calculation method of each index. The standard of a smooth river-lake network is as follows: the Edge Connectivity is larger than 2, the Edge-Node rate is larger than 1, the Connectivity Reliability is larger than 0.5, 
and the Edge Weights are larger than the Basic Edge Weight. According to different evaluation results, we can provide different planning schemes. For the stream networks with Edge Connectivity below 2, we add new channel to the systems to enhance the Edge Connectivity. For the river networks whose Edge Connectivity are larger than 2, we can enhance the Edge-Node rate, Connectivity Reliability, and Edge Weights, which is an effective method to improve the connection level.

We used the river-lake network of Fenhu industrial park in Suzhou China as an example and analyzed the connection situation using the established evaluation methodology. The result indicates that the river-lake network in Fenhu industrial park has several connectivity problems: low Edge Connectivity, narrow flow section, lack of Total River Flow Section of some lakes, and so forth. Hence, specific planning advice was provided, which includes designing new channels to link the isolated or low-node-degree lakes (such as Xiaoyue Lake and Yangwen Lake) and broadening the present narrow rivers (including 6 specific rivers). According to the calculation, after two phases of connecting plan are implemented, all connectivity indices will satisfy the standard requirements, and the connectivity of the river-lake system in Fenhu industrial park will be efficiently promoted.

The evaluation index system and planning method are notably useful in our study area. However, a limitation is worth noting. The Total River Flow Section Coefficient $\omega$ reflects the relationship between the lake volume and the Total River Flow Section of the lake; in our case study, it is defined by the interview of the front-line governor of Fenhu and our research experience. This index can be accurately calculated in future research.

\section{Data Availability}

The river data of Fenhu river-lake system were provided by Wujiang district water conservancy bureaus, which included the width, average surface elevation, bed elevation, and side slope ratio of each river. The flow section of each river was calculated from the basic river data. The lake volume data were obtained from the planning document of Wujiang Lakes Protection Planning and Basic Statistics of Lake over $50 \mathrm{mu}$. Requests for access to these data should be made to Chenguang Xiao (xiaochenguang@hhu.edu.cn).

\section{Conflicts of Interest}

The authors declare that there are no conflicts of interest.

\section{Acknowledgments}

This study has been supported by the National Key Research and Development Program of China (2017YFC040320502), a Project Funded by the Priority Academic Program Development of Jiangsu Higher Education Institutions (PAPD), and Australian Research Council for Discovery Project (Grant DP170104138).

\section{References}

[1] E. Wohl, “The significance of small streams," Frontiers of Earth Science, vol. 11, no. 3, pp. 447-456, 2017.

[2] X. Deng, Y. Xu, L. Han et al., "Impacts of urbanization on river systems in the Taihu Region, China," Water (Switzerland), vol. 7, no. 4, pp. 1340-1358, 2015.

[3] H. Zhang, Q. Wang, G. Li, H. Zhang, and J. Zhang, "Losses of ecosystem service values in the Taihu Lake Basin from 1979 to 2010," Frontiers of Earth Science, vol. 11, no. 2, pp. 310-320, 2017.

[4] P. Passalacqua, "The Delta Connectome: A network-based framework for studying connectivity in river deltas," Geomorphology, vol. 277, pp. 50-62, 2017.

[5] L. Feng, D. Wang, and B. Chen, "Water quality modeling for a tidal river network: A case study of the Suzhou River," Frontiers of Earth Science, vol. 5, no. 4, pp. 428-431, 2011.

[6] Q. Tian, Q. Wang, and Y. Liu, "Geomorphic change in Dingzi Bay, East China since the 1950s: impacts of human activity and fluvial input," Frontiers of Earth Science, vol. 11, no. 2, pp. 385396, 2017.

[7] M. C. Freeman, C. M. Pringle, and C. R. Jackson, "Hydrologic connectivity and the contribution of stream headwaters to ecological integrity at regional scales," JAWRA Journal of the American Water Resources Association, vol. 43, no. 1, pp. 5-14, 2007.

[8] E. C. Drago, A. R. Paira, and K. M. Wantzen, "Channel-floodplain geomorphology and connectivity of the lower paraguay hydrosystem," Ecohydrology \& Hydrobiology, vol. 8, no. 1, pp. 31$48,2008$.

[9] L. F. W. Lesack and P. Marsh, "River-to-lake connectivities, water renewal, and aquatic habitat diversity in the Mackenzie River Delta," Water Resources Research, vol. 46, no. 12, 2010.

[10] B. O. L. Demars, G. Wiegleb, D. M. Harper, U. Bröring, H. Brux, and W. Herr, "Aquatic plant dynamics in lowland river networks: Connectivity, management and climate change," Water (Switzerland), vol. 6, no. 4, pp. 868-911, 2014.

[11] R. W. Phillips, C. Spence, and J. W. Pomeroy, "Connectivity and runoff dynamics in heterogeneous basins," Hydrological Processes, vol. 25, no. 19, pp. 3061-3075, 2011.

[12] G. Rincón, J. Solana-Gutiérrez, C. Alonso, S. Saura, and D. García de Jalón, "Longitudinal connectivity loss in a riverine network: accounting for the likelihood of upstream and downstream movement across dams," Aquatic Sciences, vol. 79, no. 3, pp. 573-585, 2017.

[13] J. D. Phillips, W. Schwanghart, and T. Heckmann, "Graph theory in the geosciences," Earth-Science Reviews, vol. 143, pp. 147-160, 2015.

[14] P. Segurado, P. Branco, and M. T. Ferreira, "Prioritizing restoration of structural connectivity in rivers: A graph based approach," Landscape Ecology, vol. 28, no. 7, pp. 1231-1238, 2013.

[15] Z. Cui, V. Koren, N. Cajina, A. Voellmy, and F. Moreda, "Hydroinformatics advances for operational river forecasting: Using graphs for drainage network descriptions," Journal of Hydroinformatics, vol. 13, no. 2, pp. 181-197, 2011.

[16] A. E. Ilaya-Ayza, C. Martins, E. Campbell, and J. Izquierdo, "Implementation of DMAs in Intermittentwater supply networks based on equity criteria," Water (Switzerland), vol. 9, no. 11, 2017.

[17] J. Zhao, Z. Dong, and Z. Huo, "Evaluation of connectivity in channel-beach system based on graph theory," Journal of Hydraulic Engineering, vol. 42, no. 5, pp. 537-543, 2011. 
[18] G. Xu, Y. Xu, and Y. Wang, "Evaluation of river network connectivity base on flow resistance and graph theory," Advances in Water Science, vol. 23, no. 6, pp. 776-781, 2012.

[19] L. Y. Wang, Y. P. Xu, and M. J. Yu, "River System Connectivity Analysis of Wuxi's Central Urban Area Based on Graph Theory," Applied Mechanics and Materials, vol. 212-213, pp. 543-548, 2012.

[20] X. Yang, Study on Water System Connectivity Evaluation Based on Graph Theory Research in Jiaodong Area, University of Jinan, 2014.

[21] A. Tejedor, A. Longjas, I. Zaliapin, and E. Foufoula-Georgiou, "Delta channel networks: 1. A graph-theoretic approach for studying connectivity and steady state transport on deltaic surfaces," Water Resources Research, vol. 51, no. 6, pp. 3998-4018, 2015.

[22] M.-N. Yang, Y.-P. Xu, G.-B. Pan, and L.-F. Han, "Impacts of urbanization on precipitation in Taihu Lake Basin, China," Journal of Hydrologic Engineering, vol. 19, no. 4, pp. 739-746, 2014.

[23] A. Abed-Elmdoust, A. Singh, and Z.-L. Yang, "Emergent spectral properties of river network topology: An optimal channel network approach," Scientific Reports, vol. 7, no. 1, 2017. 


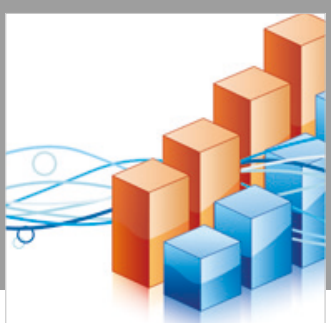

Advances in

Operations Research

\section{-n-m}
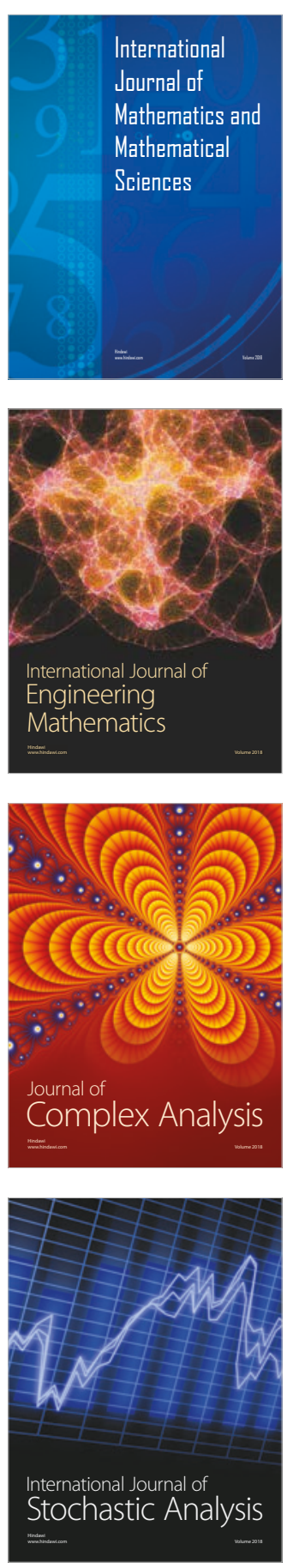
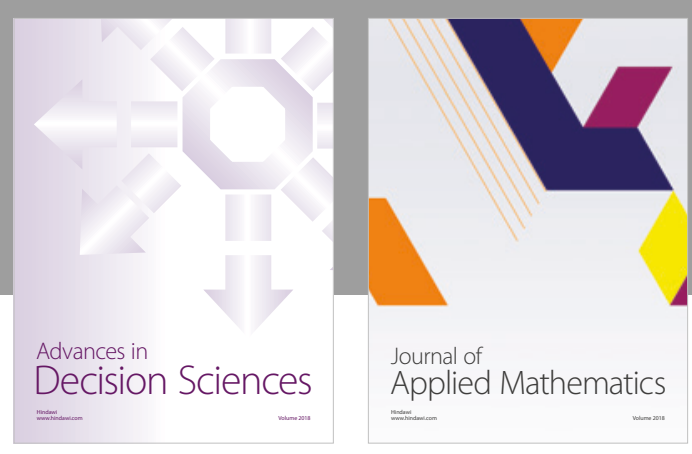

Journal of

Applied Mathematics
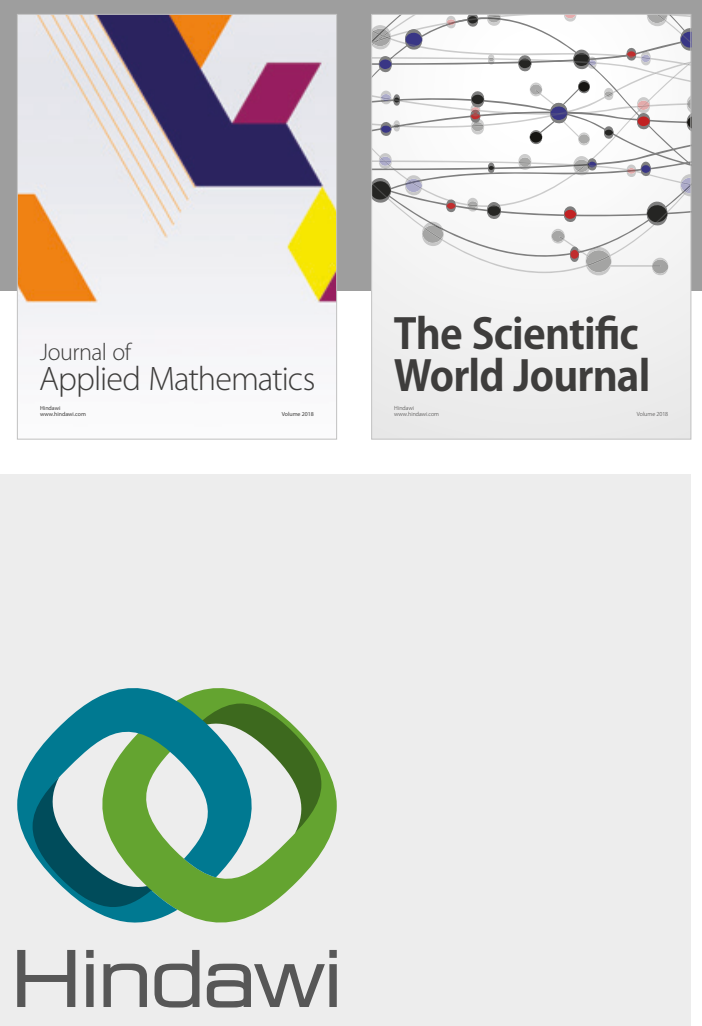

Submit your manuscripts at

www.hindawi.com

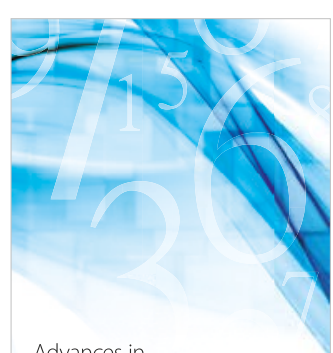

Advances in
Numerical Analysis
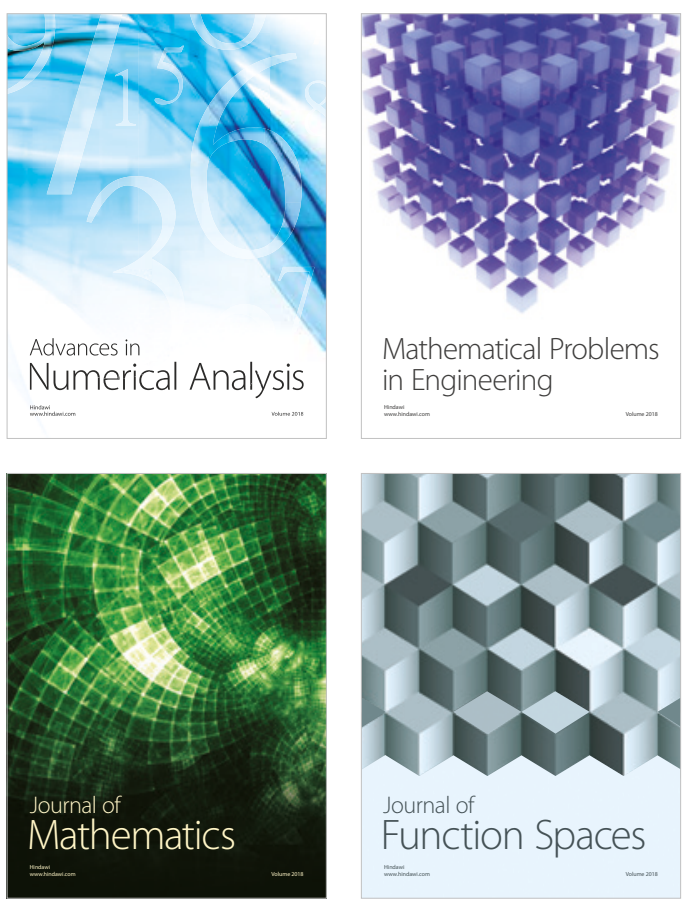

Mathematical Problems in Engineering

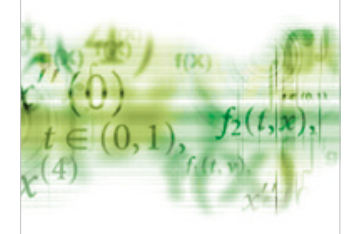

International Journal of

Differential Equations

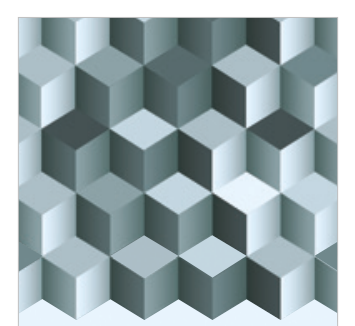

Journal of

Function Spaces

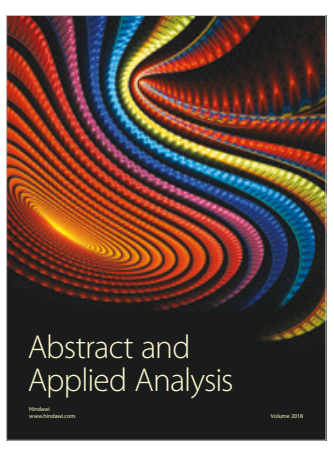

The Scientific

World Journal

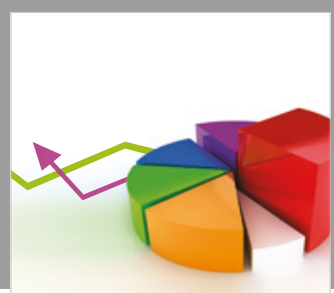

Journal of

Probability and Statistics
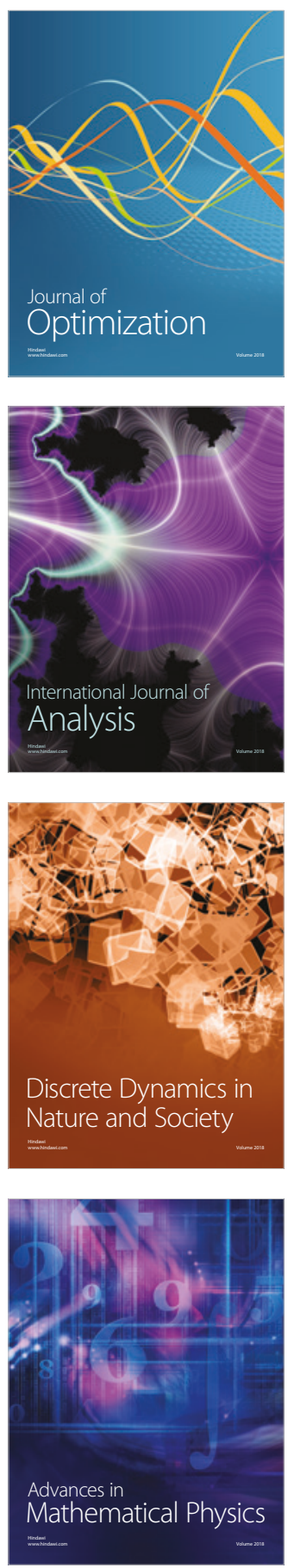